\title{
Synthesis and fluorescent properties of new derivatives of 4-amino-7-nitrobenzofurazan
}

\author{
Marioara Bem, ${ }^{a}$ Florin Badea, ${ }^{\mathrm{b}}$ Constantin Draghici, ${ }^{\mathrm{c}}$ Miron T. Caproiu, ${ }^{\mathrm{c}}$ \\ Marilena Vasilescu, ${ }^{a}$ Mariana Voicescu, ${ }^{\text {a }}$ Adrian Beteringhe, ${ }^{\text {a }}$ Agneta Caragheorgheopol, ${ }^{a}$ \\ Maria Maganu, ${ }^{c}$ Titus Constantinescu, ${ }^{a}$ and Alexandru T. Balaban ${ }^{\mathrm{d}}$ \\ "Roumanian Academy, "Ilie Murgulescu” Institute of Physical Chemistry, \\ Laboratory of Supramolecular Chemistry and Interphase Processes, Splaiul Independentei 202, \\ 060021, Roumania \\ E-mail: titelconstantinescu@yahoo.com \\ ${ }^{b}$ Politehnica University Bucharest, Department of Organic Chemistry, \\ Splaiul Independentei 313, Bucharest, Roumania \\ ${ }^{c}$ Roumanian Academy, “C. D. Nenitzescu” Institute of Organic Chemistry, NMR Department, \\ Splaiul Independentei 202 B, Bucharest, Roumania \\ ${ }^{d}$ Texas A\&M University at Galveston, 5007 Ave. U, Galveston, TX, 77553-1675, USA \\ E-mail: balabana@tamug.edu
}

\begin{abstract}
The following new compounds were obtained by reacting 4-chloro-7-nitrobenzofurazan (NBD$\mathrm{Cl}, \mathbf{1})$ with five primary amines: $3 \mathbf{b}$ with a benzo-crown ether $18 \mathrm{C} 6$; $3 \mathbf{c}$ with an $\mathrm{N}$-( $\alpha$-naphthyl)ethylenediamine group; 3d, with a 2,2,6,6-tetramethylpiperidin-N-oxyl group; 3e, with an $\alpha$ picolyl group; and 3f, derived from tris(hydroxymethyl)aminomethanol. Also, from the reaction of 1 with N-methylhydroxylamine an N-hydroxy-N-methyl-NBD derivative (3g) was prepared. All these six new NBD derivatives $\mathbf{3 b}$-g were studied (in comparison with the known compound 3a prepared from 1 and aniline) for their physical and chemical properties, with special emphasis on hydrophobicity, UV-Vis, fluorescence, using also structural studies trough QSPR.
\end{abstract}

Keywords: 4-Amino-7-nitrobenzoxadiazole derivatives, UV-Vis, fluorescence, EPR, hydrophobicity, QSPR

\section{Introduction}

Many 4-substituted-7-nitro-2,1,3-benzoxadiazoles (NBD derivatives) have a strong fluorescence which has led to their use in bioanalytical chemistry. ${ }^{1-23}$ Their benzoxadiazole ring system also been called 3,4-benzo-1,2,5-oxadiazole or benzofurazan. The usual synthesis is based on the 
nucleophilic substitution of halogens from 4-halo-7-nitrobenzofurazan, with the halogen being either chlorine (NBD-Cl) or fluorine. ${ }^{1-23}$ Some of these compounds have biological activity as antileukemic, immunosuppressive, or monoamine oxidase inhibiting activity. ${ }^{1,2,24}$

Previous papers from our laboratories have reported studies of NBD derivatives having 4aryloxy, 4-formylaryloxy groups or with amino acids. ${ }^{25-27}$ In the present article we describe the synthesis of six new NBD derivatives $(\mathbf{3 b}-\mathbf{3 g})$ prepared from $\mathrm{NBD}-\mathrm{Cl}(\mathbf{1})$ and five primary amines (2b-2f) or N-methylhydroxylamine (2g). Their properties are described and compared with the known compound $\mathbf{3 a}^{1,2,10,12,15,16}$ obtained from $\mathbf{1}$ and aniline (2a). Spectral characterization was performed by ${ }^{1} \mathrm{H}$ - and ${ }^{13} \mathrm{C}-\mathrm{NMR}$ spectrometry, IR and UV-Vis absorption spectroscopy, electron spin resonance (EPR for 3d), and the hydrophobicity was measured by reverse phase thin-layer chromatography (RP-TLC).

\section{Results and Discussion}

\section{Synthesis of compounds $\mathbf{3 a}-\mathbf{3 g}$}

Starting from 1 and primary amines such as aniline (2a), amino-benzo-crown[18C6] (2b), $N-(\alpha-$ naphthyl)-ethylenediamine dihydrochloride (2c), 4-amino-2,2,6,6-tetramethylpiperidin- $N$-oxyl (4-amino-TEMPO, 2d), 2-(methylamino)pyridine (2e), tris(hydroxymethyl)aminomethane (2f) or from N-methylhydroxylamine hydrochloride (2g), the NBD derivatives $\mathbf{3 a}-\mathbf{3 g}$ displayed in Table 1 were prepared. The reaction was carried out in a convenient solvent (methanol, ethanol, acetonitrile), under heating. For $\mathbf{3 b}-\mathbf{3 e}$ and $\mathbf{3} \mathbf{g}$ the addition of sodium hydrogen carbonate was needed. The appearance of a red-brown color and theoretical studies prove the intermediacy of Meisenheimer complex (Scheme 1), according to the literature data; ${ }^{24-26,28,29}$ in our case, the redbrown colored reaction medium, by treating with acid, turned to yellow-orange, thus proving the conversion of the Meisenheimer complex into the reaction product which could be isolated. The crystalline 3a was obtained directly, but the other compounds needed purification by preparative TLC.

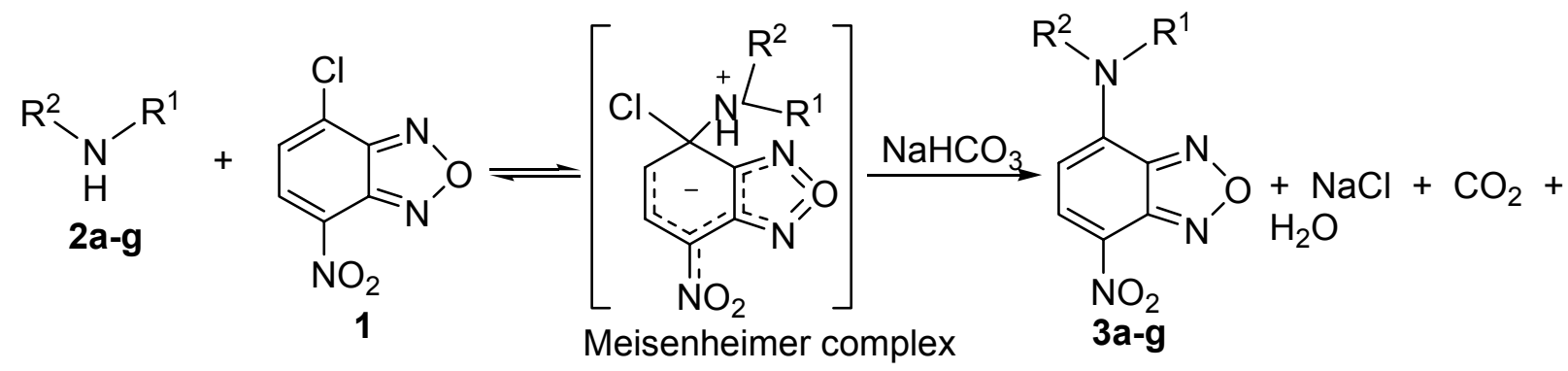

Scheme 1. Synthesis of compounds $\mathbf{3 a}-\mathbf{3 g}$. 
Table 1. Structures of the NBD derivatives $\mathbf{3 a}-\mathbf{g}$

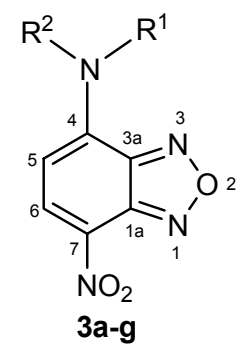

Compound 3 3b 3 ce

NMR Spectra of compounds $3 \mathbf{a}-\mathbf{g}$

The NMR data of compounds 3a-c, 3e-g (Table 2) confirm the proposed structure. 
Table 2. ${ }^{1} \mathrm{H}-\mathrm{NMR}$ and ${ }^{13} \mathrm{C}$ - NMR data of compounds 3a-g $(\delta \mathrm{ppm} ; J \mathrm{~Hz})$

\begin{tabular}{|c|c|}
\hline Compound & NMR-spectra \\
\hline 3a & 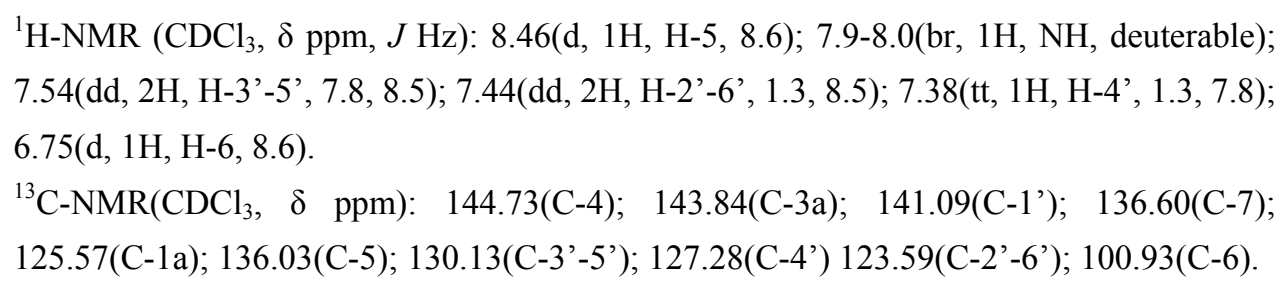 \\
\hline $3 b$ & 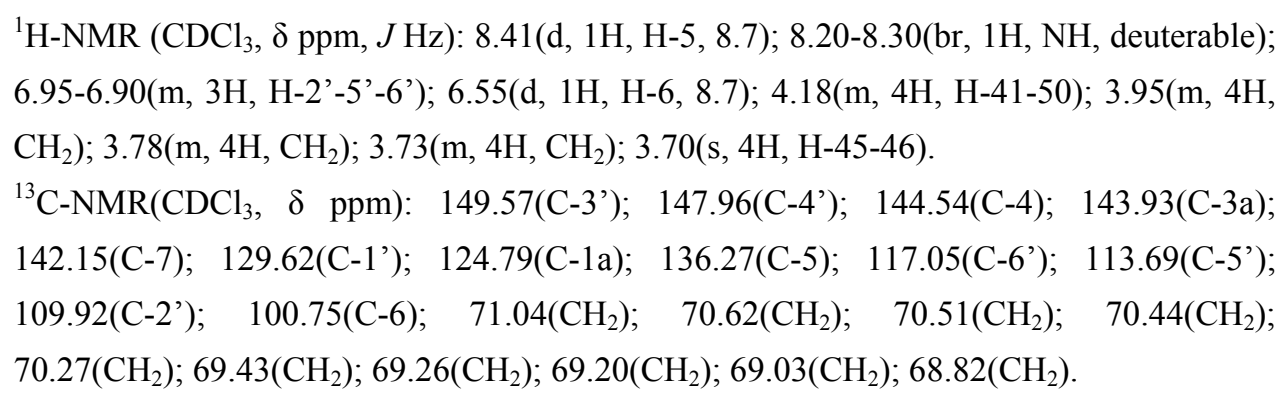 \\
\hline
\end{tabular}

${ }^{1} \mathrm{H}-\mathrm{NMR}$ (dmso-d $\left.6, \delta \mathrm{ppm}, J \mathrm{~Hz}\right): 9.50(\mathrm{br}, 1 \mathrm{H}, \mathrm{NH}$, deuterable); 8.42(d, $1 \mathrm{H}, \mathrm{H}-5,8.9$ ); 8.06(dd, 1H, H-18, 1.0, 7.1); 7.74(dd, 1H, H-15, 1.2, 6.4); 7.40(m, 2H, H-16-17); 7.29(t, $1 \mathrm{H}, \mathrm{H}-12,7.7) ; 7.11(\mathrm{~d}, 1 \mathrm{H}, \mathrm{H}-13,7.7) ; 6.62(1 \mathrm{H}, \mathrm{H}-11,7.7) ; 6.41(\mathrm{~d}, \mathrm{H}-6,8.9) ; 3.80(\mathrm{br}$, 2H, H-9); 3.60(t, 2H, H-8, 5.8).

${ }^{1} \mathrm{H}-\mathrm{NMR}\left(\mathrm{CDCl}_{3}, \delta \mathrm{ppm}, J \mathrm{~Hz}\right): 8.39(\mathrm{~d}, 1 \mathrm{H}, \mathrm{H}-5,8.6) ; 7.84(\mathrm{~m}, 2 \mathrm{H}, \mathrm{H}-13-15)$; $3 \mathbf{c}$

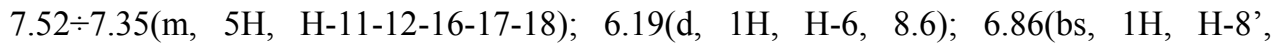
deuterable); 6.70(bs, $1 \mathrm{H}, \mathrm{H}-9$ ', deuterable); 3.92(bs, 2H, H-9); 3.82(t, $2 \mathrm{H}, \mathrm{H}-8,6.2$ ).

${ }^{13} \mathrm{C}-\mathrm{NMR}$ (dmso-d 6 , $\delta$ ppm): 145.32(Cq-10); 144.38(Cq-4); 143.47(Cq-3a); 137.92(Cq-7); 134.08(Cq-14); 123.07(Cq-1a); 120.86(Cq-19);137.81(C-5); 99.23(C-6); 128.03(C-15); 126.78(C-12); 125.70(C-17); 124.08(C-18); 121.44(C-16); 115.91(C-13); 103.13(C$11) ; 42.25(\mathrm{C}-8$ or C-9); $41.41(\mathrm{C}-9$ or $\mathrm{C}-8)$.

${ }^{1} \mathrm{H}-\mathrm{NMR}\left(\mathrm{CDCl}_{3}+\mathrm{TFA}, \delta \mathrm{ppm}, J \mathrm{~Hz}\right): 8.39(\mathrm{~d}, 1 \mathrm{H}, \mathrm{H}-5,8.7) ; 8.02(\mathrm{dd}, 1 \mathrm{H}, \mathrm{H}-11,8.4,0.9)$; 7.98(m, 2H, H-18-16); 7.70(dd, 1H, H-13, 0.9, 7.6); 7.65(m, 2H, H-15-17); 7.52(dd, $1 \mathrm{H}$, $\mathrm{H}-12,7.7,8.8) ; 6.26(\mathrm{~d}, 1 \mathrm{H}, \mathrm{H}-6,8.7) ; 4.18(\mathrm{~s}, 4 \mathrm{H}, \mathrm{H}-8$ and $\mathrm{H}-9)$.

$3 \mathbf{c}$ in TFA

${ }^{13} \mathrm{C}-\mathrm{NMR}\left(\mathrm{CDCl}_{3}+\mathrm{TFA}, \quad \delta \quad \mathrm{ppm}\right): \quad 144.13(\mathrm{Cq}-10) ; \quad 143.83(\mathrm{Cq}-4) ; \quad 143.43(\mathrm{Cq}-3 \mathrm{a})$; 134.69(Cq-7); $\quad 134.68(\mathrm{Cq}-14) ; \quad 124.93(\mathrm{Cq}-1 \mathrm{a}) ; \quad 124.33(\mathrm{Cq}-19) ; \quad 136.81(\mathrm{CH}-5)$; 131.75(CH); $\quad 129.78(\mathrm{CH}) ; \quad 129.08(\mathrm{CH}) ; \quad 128.01(\mathrm{CH}) ; \quad 125.24(\mathrm{CH}) ; \quad 121.44(\mathrm{CH}) ;$ $118.55(\mathrm{CH}) ; 100.62(\mathrm{CH}-6) ; 51.08(\mathrm{C}-9) ; 40.00(\mathrm{C}-8)$.

${ }^{1} \mathrm{H}-\mathrm{NMR}\left(\mathrm{dmso}_{\mathrm{d}}, \delta \mathrm{ppm}, J \mathrm{~Hz}\right): 9.9(\mathrm{br}, 1 \mathrm{H}, \mathrm{HN}) ; 8.53(\mathrm{dd}, 1 \mathrm{H}, \mathrm{H}-13,1.0,4.6) ; 8.5(\mathrm{~d}$, $3 e$ $1 \mathrm{H}, \mathrm{H}-5,8.9) ; 7.78(\mathrm{td}, 1 \mathrm{H}, \mathrm{H}-11,7.8,1.0) ; 7.42(\mathrm{~d}, 1 \mathrm{H}, \mathrm{H}-10,7.8) ; 7.31$ (dd, $1 \mathrm{H}, \mathrm{H}-12,4.6$, 7.8); 6.33(d, $1 \mathrm{H}, \mathrm{H}-6,8.9) ; 4.80(\mathrm{br}, 2 \mathrm{H}, \mathrm{H}-8)$.

${ }^{13} \mathrm{C}-\mathrm{NMR}\left(\mathrm{dmso}_{6}, \delta \mathrm{ppm}\right): 156.26(\mathrm{C}-9) ; 149.39(\mathrm{C}-13) ; 145.17(\mathrm{C}-4) ; 144.12(\mathrm{C}-3 \mathrm{a})$; 
138.61(C-7); 137.97(C-5); 137.36(C-11)；122.98(C-10)；121.80(C-12)；125.97(C-1a); 100.09(C-6); 48.31(C-8).

${ }^{1} \mathrm{H}-\mathrm{NMR}$ (dmso-d $\left.{ }_{6}, \delta \mathrm{ppm}, J \mathrm{~Hz}\right): 8.51(\mathrm{~d}, 1 \mathrm{H}, \mathrm{H}-5,9.0) ; 7.54(\mathrm{br}, 1 \mathrm{H}, \mathrm{NH}$, deuterable); 6.86(d, 1H, H-6, 9.0); 5.13(t, 3H, HO, deuterable, 5.4); 3.77(d, 6H, H-9-10-11, 5.4).

3f

${ }^{13} \mathrm{C}-\mathrm{NMR}\left(\mathrm{dmso}_{6}, \delta \mathrm{ppm}\right): 145.39(\mathrm{C}-4) ; 144.52(\mathrm{C}-3 \mathrm{a}) ; 143.88(\mathrm{C}-7) ; 137.93(\mathrm{C}-5)$; 121.13(C-1a); 102.30(C-6); 64.73(C-9-10-11); 64.13(C-8).

${ }^{1} \mathrm{H}-\mathrm{NMR}$ (dmso-d6, $\left.\delta \mathrm{ppm}, J \mathrm{~Hz}\right): 9.50(\mathrm{br}, 1 \mathrm{H}, \mathrm{OH}$, deuterable); 8.50(d, 1H, H-5, 8.7); 6.29(d, 1H, H-6, 8.7); 3.05(d, 3H, H-8, 4.0).

$3 g$

${ }^{13} \mathrm{C}-\mathrm{NMR}\left(\mathrm{dmso}_{6}, \quad \delta \mathrm{ppm}\right): 145.71(\mathrm{C}-4) ; 144.23(\mathrm{C}-3 \mathrm{a}) ; 144.02(\mathrm{C}-7) ; 137.88(\mathrm{C}-5)$; 120.89(C-1a); 98.97(C-6); 30.14(C-8).

Assignments in Table 2 are using the atom numbering indicated in Table 1. No NMR data are reported for the paramagnetic compound 3d. Compound 3c, with two amino groups, is converted into an ammonium salt by protonation of the naphthylamino group (the strongly electronwithdrawing NBD group cancels the basicity of the adjacent amino group). The changes in the NMR spectra are evident - there are significant differences for C-9 and protons $\mathrm{H}-8$ and H-9 in the ethylene group, small changes for H-11 in the naphthyl group, and no changes in the NBD moiety.

\section{Hydrophobic/hydrophilic balance of compounds 3a-g}

All biological uses of chemical compounds depend on how they interact with biomembranes, and such interactions are governed by the hydrophobic/hydrophilic balance, so that we had to include such effects in the present study. Following previous reports, ${ }^{25,26}$ the hydrophobic/hydrophilic balance of compounds 3a-g was studied experimentally by reverse phase TLC (RP-TLC), a simple, efficient, and precise method. The molecular hydrophobicity $\mathrm{R}_{\mathrm{M} 0}$ was determined by means of equations (1) and (2), using the data presented in Table 3.

$$
\begin{aligned}
& \mathrm{R}_{\mathrm{M}}=\log \left(1 / \mathrm{R}_{\mathrm{f}}-1\right) \\
& \mathrm{R}_{\mathrm{M}}=\mathrm{R}_{\mathrm{M} 0}+\mathrm{bK}
\end{aligned}
$$

The hydrophobicity of compounds 3a-g decreases in the order $\mathbf{3 c}>\mathbf{3 a}>\mathbf{3 d}>\mathbf{3 e}>\mathbf{3 g}>\mathbf{3 b}>$ 3f (hydrophilicity increasing obviously in the reverse order). The NBD group has $\log \mathrm{P}=1.69 .^{35}$ The remaining $\mathrm{R}^{1} \mathrm{R}^{2} \mathrm{~N}$ moiety combines its effect leading to increased hydrophobicity due to the presence of phenyl, naphthyl, pyridine and 2,2,6,6-tetramethylpiperidyl (3a, 3c-e) or to decreased hydrophobicity in the presence of $\mathrm{OH}$ groups and the crown ether macrocycle $(\mathbf{3 b}, \mathbf{3 f}$, 3g). 
Table 3. Experimental hydrophobicity $\left(\mathrm{R}_{\mathrm{M} 0}, \mathrm{~b}\right)^{\mathrm{a}}$ and calculated $(\log \mathrm{P})^{30}$ for $\mathbf{3 a}-\mathbf{g}$

\begin{tabular}{|c|c|c|c|c|c|c|c|c|c|c|}
\hline \multirow{3}{*}{ Comp. } & \multicolumn{9}{|c|}{ Exp. } & \multirow{3}{*}{$\begin{array}{l}\text { Calcd } \\
\log P\end{array}$} \\
\hline & \multicolumn{4}{|c|}{$\mathrm{R}_{\mathrm{M}}$ in aqueous ethanol, conc.(v/v) } & \multirow{2}{*}{$R_{M 0}$} & \multirow{2}{*}{$b$} & \multicolumn{3}{|c|}{ Statistical parameters } & \\
\hline & $80 \%$ & $70 \%$ & $60 \%$ & $50 \%$ & & & $R$ & $F$ & $S D$ & \\
\hline $3 \mathbf{a}$ & -0.508 & -0.281 & 0.067 & 0.407 & 1.932 & -0.031 & -0.996 & 238 & 0.045 & 4.39 \\
\hline $\mathbf{3 b}$ & 0.103 & 0.097 & 0.216 & 0.320 & 0.685 & -0.010 & -0.939 & 14 & 0.145 & 3.34 \\
\hline $3 c$ & -0.447 & -0.165 & 0.301 & 0.733 & 2.708 & -0.040 & -0.995 & 202 & 0.063 & 5.18 \\
\hline 3d & -0.574 & -0.281 & 0.067 & 0.322 & 1.857 & -0.030 & -0.998 & 641 & 0.020 & 3.92 \\
\hline $3 e$ & -0.508 & -0.407 & -0.112 & 0.281 & 1.543 & -0.027 & -0.971 & 32 & 0.104 & 2.94 \\
\hline $3 f$ & -1.255 & -0.985 & -0.740 & -0.619 & 0.497 & -0.021 & -0.987 & 76 & 0.055 & 1.80 \\
\hline $3 g$ & -0.727 & -0.553 & -0.301 & -0.084 & 1.001 & -0.022 & -0.998 & 436 & 0.023 & 2.68 \\
\hline
\end{tabular}

a) Silica gel RP-18 $\mathrm{F}_{254}$ (Merck); $\mathrm{R}_{\mathrm{M} 0}=$ molecular hydrophobicity (eq. 2); $b=$ change in $\mathrm{R}_{\mathrm{M}}$ value caused by increasing the concentration $(\mathrm{K})$ of the organic component in the mobile phase (eq. 1); $R=$ correlation coefficient for parameters $\mathrm{R}_{\mathrm{M} 0}$ and $b$ in eq. $2 .{ }^{31-34}$

On calculating $\log \mathrm{P}$ values using fragmental constants, ${ }^{30}$ a relatively good correlation $\left(R^{2}=0.857\right)$ with experimental data for $R_{\mathrm{M} 0}$ was obtained for compounds $\mathbf{3 a}-\mathbf{g}$ (Figure 1 ).

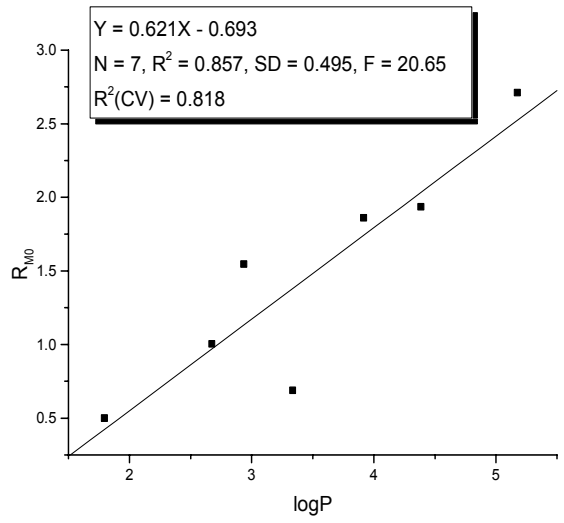

Figure 1. $R_{M 0} v s \log \mathrm{P}$ for compounds $\mathbf{3 a}-\mathbf{g}$.

\section{Electronic absorption spectra and fluorescence of compounds 3a-g}

\section{UV-Vis spectra}

Compounds $\mathbf{3 a}-\mathbf{g}$ are reddish or brown in crystalline state, and their solutions in organic solvents are yellow, orange, or red. All are soluble in absolute ethanol, so that one can make comparisons between their electronic absorption bands. As seen from Table 4, all compounds present a strong band in the visible region $\left(\lambda_{\max }=457-483 \mathrm{~nm}\right)$ due to the NBD chromophore. ${ }^{3,25}$ The differences are due to extended conjugation with the acceptor NBD group ${ }^{10,24,36}$ for aromatic 
susbtituents at the amino group (3a, 3b, which absorb at higher wavelengths), whereas the remaining compounds having alkyl, hydroxy, or aralkyl groups absorb at lower wavelengths.

Calculated Mulliken net atomic charges on the amino nitrogen $\left(\mathrm{NAC}_{\mathrm{N}}\right)$ using the AM1 algorithm for molecular geometries, ${ }^{37}$ and the CODESSA program ${ }^{38}$ are presented in Table 5 together with the values found by a simple linear correlation, eq. (3), where $\mathrm{NAC}_{\mathrm{N}}$ is the net atomic charge for the nitrogen atom, and SD is the standard deviation (calculated and experimental values had two decimals).

$$
\begin{gathered}
\lambda_{\max }(\text { calc. })=-145.9( \pm 25.72) \mathrm{NAC}_{\mathrm{N}}+434.9 \\
\mathrm{~N}=7 ; R^{2}=0.865 ; \mathrm{SD}=3.648 ; \mathrm{F}=32.2 ; R_{\text {cross-valid. }}^{2}=0.815
\end{gathered}
$$

\begin{tabular}{|c|c|c|c|}
\hline Comp. & Conc.(M) & $\lambda_{\max }(\mathrm{nm})$ & $\varepsilon \times 10^{3}\left(\mathrm{~L} \times \mathrm{mole}^{-1} \times \mathrm{cm}^{-1}\right)$ \\
\hline $\mathbf{3 a}$ & $1.21 \times 10^{-4}$ & $\begin{array}{c}279(\mathrm{sh}) \\
330 \\
475\end{array}$ & $\begin{array}{c}2.80 \\
6.28 \\
17.60\end{array}$ \\
\hline $\mathbf{3 b}$ & $1.20 \times 10^{-4}$ & $\begin{array}{l}279 \\
334 \\
483\end{array}$ & $\begin{array}{l}2.16 \\
2.75 \\
6.75\end{array}$ \\
\hline $3 c$ & $4.25 \times 10^{-4}$ & $\begin{array}{l}333 \\
465\end{array}$ & $\begin{array}{l}1.08 \\
1.43\end{array}$ \\
\hline 3d & $4.25 \times 10^{-4}$ & $\begin{array}{l}331 \\
464\end{array}$ & $\begin{array}{l}1.08 \\
2.23\end{array}$ \\
\hline $3 e$ & $4.25 \times 10^{-4}$ & $\begin{array}{c}261(\mathrm{sh}) \\
326 \\
457\end{array}$ & $\begin{array}{c}0.611 \\
0.752 \\
1.88\end{array}$ \\
\hline $3 f$ & $1.43 \times 10^{-4}$ & $\begin{array}{c}265(\mathrm{sh}) \\
330 \\
463\end{array}$ & $\begin{array}{l}1.39 \\
3.49 \\
7.83\end{array}$ \\
\hline $3 g$ & $4.25 \times 10^{-4}$ & $\begin{array}{l}332 \\
462\end{array}$ & $\begin{array}{l}1.41 \\
2.96\end{array}$ \\
\hline
\end{tabular}

Table 4. UV-Vis spectral data of compounds $\mathbf{3 a}-\mathbf{g}$ in absolute ethanol 
Table 5. Net atomic charges on the amino nitrogen $\left(\mathrm{NAC}_{\mathrm{N}}\right)$, and $\lambda_{\max }$ (exp. in Table 4 and calc. with eq. 3 , in $\mathrm{nm}$ ) for compounds $\mathbf{3 a}-\mathbf{g}$ in absolute ethanol

\begin{tabular}{ccccc}
\hline Compound & $\mathrm{NAC}_{\mathrm{N}}$ & $\lambda_{\max }(\exp )^{\mathrm{a}}$ & $\lambda_{\max }($ calc. $)$ & Residual \\
\hline 3a & -0.285 & 475 & 476 & -0.59 \\
3b & -0.294 & 483 & 477 & 6.18 \\
3c & -0.229 & 465 & 468 & -3.24 \\
3d & -0.216 & 464 & 466 & -1.83 \\
3e & -0.126 & 457 & 453 & 3.66 \\
3f & -0.204 & 463 & 464 & -1.78 \\
3g & -0.185 & 462 & 462 & 0.48 \\
\hline
\end{tabular}

${ }^{\mathrm{a}}$ see Table 4

Compound $\mathbf{3 b}$ with the $18 \mathrm{C} 6$ is able to form complexes with some alkali cations. ${ }^{39,40}$ Indeed, an acetonitrile solution of compound $\mathbf{3 b}$ undergoes a slight hypsochromic shift on treatment with potassium perchlorate (molar ratiol:1) from $480 \mathrm{~nm}$ to $477 \mathrm{~nm}$, with an isosbestic point at $\lambda=514$ nm.

\section{General characteristics for the fluorescence of compounds $3 a-g$}

It is known that NBD compounds with a 4-alkylamino substituent are fluorescent, ${ }^{1-23,41}$ but only weakly fluorescent when they have a 4-arylamino substituent such as phenyl (3a). ${ }^{1,2,10,12,15,16}$ Among compounds $\mathbf{3 a}-\mathbf{g}$, only compounds $\mathbf{3 e - g}$ are strongly fluorescent in solid state and in most solvents. Compounds 3a and 3d are weakly fluorescent in solid state and in most solvents. Compound $\mathbf{3 b}$ is not fluorescent either pure or as complex with $\mathrm{KClO}_{4}$. Compound $\mathbf{3 c}$ is not fluorescent in solid state, but is weakly fluorescent in some solvents (e. g. dichloromethane, benzene, and toluene); a more detailed account will be seen below.

By choosing the excitation wavelength at $\lambda_{\mathrm{ex}}=450 \mathrm{~nm}$ and absolute ethanol as solvent $\left(\mathrm{E}_{\mathrm{T}}(30)=51.9\right),{ }^{42}$ the characteristic data for the fluorescence of compounds are presented in Table 6. One can observe that the emission wavelength $\left(\lambda_{\mathrm{em}}=524-545 \mathrm{~nm}\right)$ agrees with the known range for NBD derivatives. ${ }^{1-23,41}$ The $\lambda_{\text {em }}$ values decrease in the order $\lambda_{\mathrm{em}} \mathbf{3 a}>\lambda_{\mathrm{em}} \mathbf{3 d}=\lambda_{\mathrm{em}} \mathbf{3 f}>$ $\lambda_{\text {em }} \mathbf{3 e}>\lambda_{\text {em }} \mathbf{3 g}$; the quantum yields $(\Phi)$ decrease in the order $\Phi \mathbf{3 e}>\Phi \mathbf{3 f}>\Phi \mathbf{3 g}>\Phi \mathbf{3 d}$ $>\Phi$ 3a (the last compound has a very low a value); the natural lifetimes $\left(\tau_{0}\right)$ decrease in the order $\tau_{0} \mathbf{3 e}>\tau_{0} \mathbf{3} \mathbf{d}>\tau_{0} \mathbf{3 g}>\tau_{0} \mathbf{3 f}$; and the calculated lifetimes $(\tau)$ according to the Strickler-Berg formula (4) ${ }^{43}$ which involves the quantum yield $(\Phi)$ decrease in the order: $\tau \mathbf{3 e}>\tau \mathbf{3 g}>\tau \mathbf{3 f}>\tau$ 3d.

$$
\frac{1}{\tau_{0}}=2.88 \times 10^{-9} n^{2} \frac{\int I_{F}\left(v_{F}\right) d v_{F}}{\int I_{F}\left(v_{F}\right) v_{F}^{-3} d v_{F}} \times \int \frac{\varepsilon\left(v_{A}\right)}{v_{A}} d v_{A}
$$

where: $\tau_{0}$ is the lifetime, $v$ is the wavenumber of the maximum of the absorption band, $n$ is the refractive index of the solvent (1.3595 for ethanol), $I_{F}$ is the fluorescence intensity, $\varepsilon$ is the molar absorption coefficient, and $\tau=\tau_{0} \cdot \Phi$. 
In the case of the paramagnetic compound $\mathbf{3 d}$ one must ascribe the quenching of fluorescence to an intermolecular process, similarly to literature data, due to the 4-amino-TEMPO free radical. $^{44-46}$

Table 6. Fluorescence characteristics $\lambda_{\mathrm{em}}$, quantum yield $(\Phi)$, natural lifetime $\left(\tau_{0}\right)$, and calculated lifetime $(\tau)$ in absolute ethanol for compounds 3a, 3d-g for $\lambda_{\mathrm{ex}}=450 \mathrm{~nm}$

\begin{tabular}{ccccc}
\hline Compound & $\lambda_{\mathrm{em}}(\mathrm{nm})$ & $\Phi^{\mathrm{a}, \mathrm{b}}$ & $\tau_{0}(\mathrm{~ns})$ & $\tau(\mathrm{ns})$ \\
\hline 3a & 545 & Very low $^{\mathrm{c}}$ & & \\
3d & 531 & 0.0016 & 79.05 & 0.13 \\
$\mathbf{3 e}$ & 526 & 0.0587 & 104 & 6.10 \\
$\mathbf{3 f}$ & 531 & 0.0393 & 24.5 & 0.96 \\
$\mathbf{3 g}$ & 524 & 0.0298 & 62.6 & 1.86 \\
\hline
\end{tabular}

${ }^{\mathrm{a}}$ conc. $(\mathbf{3 a})=1.21 \times 10^{-4} \mathrm{M}$, conc. $(\mathbf{3 d}, \mathbf{3 e}, \mathbf{3 g})=4.25 \times 10^{-4} \mathrm{M}$; conc. $(\mathbf{3 f})=1.43 \times 10^{-4} \mathrm{M}$

${ }^{\mathrm{b}}$ compared to the quinine bisulfate (in $0.1 \mathrm{~N} \mathrm{H}_{2} \mathrm{SO}_{4}, \Phi=0.55$ )

c $2.03 \times 10^{-5} \mathrm{~mol} / \mathrm{L}$

As discussed above, the electronic absorption spectra, for the three compounds $\mathbf{3 d}, \mathbf{3 e}, \mathbf{3 g}$ that have a significant fluorescence, it was possible to correlate the fluorescence lifetime $\tau$ (which involves also the quantum yield) with the calculated net atomic charge for the amino nitrogen atom $\left(\mathrm{NAC}_{\mathrm{N}}\right)$ by the equation (5), as seen in Table 7.

$$
\begin{gathered}
\tau=67.32( \pm 4.791) \mathrm{NAC}_{\mathrm{N}}+14.53( \pm 0.837) \\
\mathrm{N}=3 \quad \mathrm{R}^{2}=0.995 \mathrm{SD}=0.275 \quad \mathrm{~F}=197.4 \quad \mathrm{R}_{\text {cross-valid. }}^{2}=0.980
\end{gathered}
$$

Table 7. Calculated values of net atomic charge on the amino nitrogen $\left(\mathrm{NAC}_{\mathrm{N}}\right)$ by CODESSA program and $\tau$ (exp. in Table 6 and calc. with eq. 5) for compounds 3e-g

\begin{tabular}{ccccc}
\hline Compounds & $\mathrm{NAC}_{\mathrm{N}}$ & $\tau(\exp .)^{\mathrm{a}}$ & $\tau($ calc. $)$ & Resid. \\
\hline $\mathbf{3 e}$ & -0.126 & 6.10 & 6.05 & 0.05 \\
$\mathbf{3 f}$ & -0.204 & 0.96 & 0.80 & 0.16 \\
$\mathbf{3 g}$ & -0.185 & 1.86 & 2.07 & -0.21 \\
\hline
\end{tabular}

${ }^{\text {a) }}$ See Table 6

\section{Fluorescence of compound 3d}

The paramagnetic compound 3d is weakly fluorescent due to intermolecular quenching. The EPR spectrum has three lines (Figure 2) due to a hyperfine coupling with $\mathrm{a}_{\mathrm{N}}=14.79$ Gauss (in methylene chloride) in agreement with that of 4-amino-TEMPO. ${ }^{47}$ 


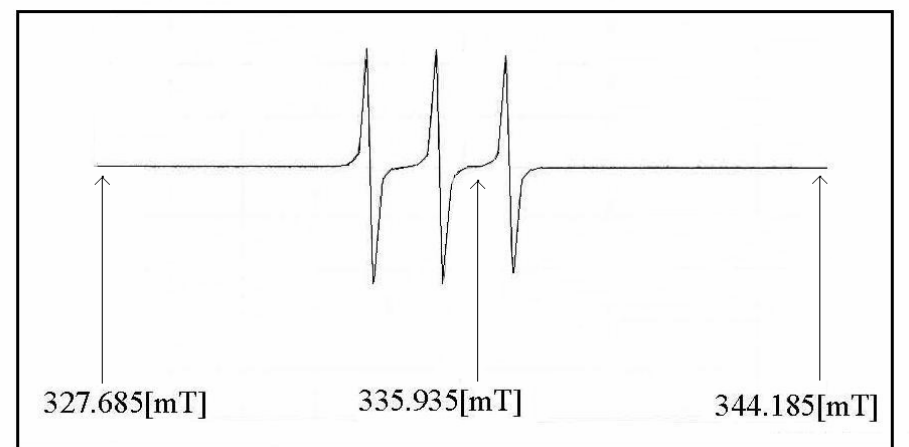

Figure 2. EPR spectrum of $\mathbf{3 d}$ in dichloromethane.

With an excess of ascorbic acid in absolute ethanol, the solution becomes strongly fluorescent in a few minutes (the intensity of the fluorescence increases about six times, as seen in Figure 3), due to the formation of hydroxylamine 4 (Scheme 2). Compound 4 was detected by TLC $\left(R_{\mathrm{f}} \mathbf{3 d}=0.907, \mathrm{R}_{\mathrm{f}} \mathbf{4}=0.372\right.$, on silica gel with methylene chloride:methanol 9.5:0.5 v/v). The process described in Scheme 2 is reversible, because oxidation of 4 (with $\mathrm{PbO}_{2}, \mathrm{Ag}_{2} \mathrm{O}$, $\mathrm{KMnO}_{4}$, even with air) produces $3 \mathbf{d}$.

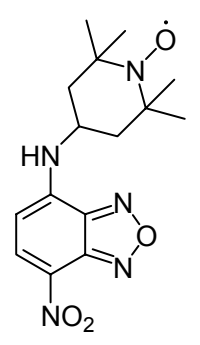

3d

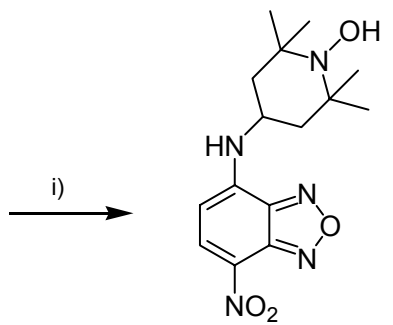

4

Scheme 2. Reduction of $\mathbf{3 d}$ ( $i=$ ascorbic acid, molar ratio $\mathbf{3 d}$ : ascorbic acid =1:6).

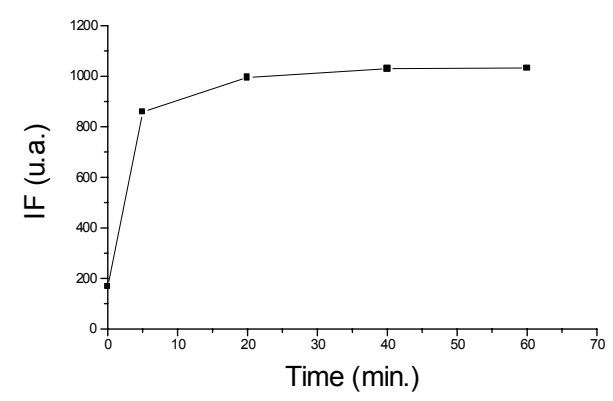

Figure 3. Variation of the fluorescence intensity $\left(\mathrm{I}_{\mathrm{F}}\right)$ during the reduction of $\mathbf{3 d}$ (in absolute ethanol) with an excess of ascorbic acid. 
These fluorescence and paramagnetic properties of compound 3d may lead to applications as a molecular probe for biological redox processes.

\section{Fluorescence of compound 3c}

In absolute ethanol, compound $\mathbf{3 c}$ is not fluorescent, but in less polar solvents (benzene, toluene) a weak fluorescence (Table 8$)$ due to the NBD group was detected $\left(\lambda_{\text {ex }}=450 \mathrm{~nm}, \lambda_{\text {em }}=505-512\right.$ $\mathrm{nm})$.

In acetic acid which has the same polarity as absolute ethanol, a weak fluorescence has also been observed. However, the fluorescence increases significantly in the presence of strong acids such as trifluoroacetic acid and 4-toluenesulfonic acid (Table 9), when the $\alpha$-naphthylamino group becomes protonated affording cation 5 (Scheme 3). Trifluoroacetic acid introduces a significant hypsochromic shift $(16 \mathrm{~nm})$ in the visible spectrum, and the protonated compound $\mathbf{5}$ has the highest value for $\Phi$ (Table 9).

Table 8. The effect of solvent polarity on the absorption and fluorescence spectra of compound 3c (using $\lambda_{\mathrm{ex}}=450 \mathrm{~nm}$ )

\begin{tabular}{|c|c|c|c|c|c|}
\hline $\begin{array}{c}\text { Solvent } \\
\text { and } \\
\mathrm{E}_{\mathrm{T}}(30)^{42}\end{array}$ & $\begin{array}{l}\text { Conc. of } \\
\text { compound } \\
\text { 3c }(\mathrm{M})\end{array}$ & $\begin{array}{l}\lambda_{\max } \\
(\mathrm{nm})\end{array}$ & $\begin{array}{c}\varepsilon \times 10^{3} \\
\left(\mathrm{~L} \times \mathrm{mol}^{-1} \times \mathrm{cm}^{-1}\right)\end{array}$ & $\begin{array}{l}\lambda_{\mathrm{em}} \\
(\mathrm{nm})\end{array}$ & $\Phi^{\mathrm{a}}$ \\
\hline $\begin{array}{l}\text { Ethanol } \\
(51.9)\end{array}$ & $4.25 \times 10^{-4}$ & $\begin{array}{l}465 \\
333\end{array}$ & $\begin{array}{l}1.43 \\
1.08\end{array}$ & none & none \\
\hline $\begin{array}{l}\text { Dichloromethane } \\
\text { (41.1) }\end{array}$ & $1 \times 10^{-4}$ & $\begin{array}{l}452 \\
326\end{array}$ & $\begin{array}{l}15.2 \\
11.2\end{array}$ & 513 & very low \\
\hline $\begin{array}{l}\text { Benzene } \\
(34.5)\end{array}$ & $1 \times 10^{-4}$ & $\begin{array}{l}447 \\
322\end{array}$ & $\begin{array}{l}9.8 \\
8.3\end{array}$ & 506 & 0.00100 \\
\hline $\begin{array}{c}\text { Toluene } \\
(33.9)\end{array}$ & $1 \times 10^{-4}$ & $\begin{array}{l}445 \\
320 \\
\end{array}$ & $\begin{array}{l}9.7 \\
8.4 \\
\end{array}$ & 508 & 0.00112 \\
\hline
\end{tabular}

a compared to quinine bisulfate (in $0.1 \mathrm{~N} \mathrm{H}_{2} \mathrm{SO}_{4}, \Phi=0.55$ ); ${ }^{\mathrm{b}} 5.035 \times 10^{-4} \mathrm{M}$

In compound $\mathbf{3 c}$ there is an electron-acceptor NBD group (A) and a $\pi$-electron-donor moiety (D) represented by the $\alpha$-naphthylamino group, linked together by a flexible ethylenediamino chain. An intramolecular D-A interaction will quench the fluorescence, but the protonation cancels the donor effect of the donor group.

By simulating the molecular geometry using the Hyperchem force field $\mathrm{MM}+{ }^{48}$ it was possible to simulate the closed-sandwich geometry of $\mathbf{3 c}$ as a consequence of the intramolecular D-A interaction. As seen in an earlier Section, NMR data (Table 2) confirm the structure of the salt 5 , and its geometry appears as an open structure without such an intramolecular D-A interaction (Scheme 3 and Fig. 4). 
Table 9. The fluorescence of $3 \mathbf{c}\left(1 \times 10^{-4} \mathrm{M}\right)$ in absolute ethanol with acids, $\lambda_{\mathrm{ex}}=450 \mathrm{~nm}$

\begin{tabular}{ccccc}
\hline Acid & $\lambda_{\max }(\mathrm{nm})$ & $\begin{array}{c}\mathrm{E} \times 10^{3} \\
\left(\mathrm{~L} \times \mathrm{mol}^{-1} \times \mathrm{cm}^{-1}\right)\end{array}$ & $\begin{array}{c}\lambda_{\text {em }} \\
(\mathrm{nm})\end{array}$ & $\Phi^{\mathrm{e}}$ \\
\hline $\mathrm{TFA}^{\mathrm{a}}: \mathrm{EtOH}^{\mathrm{b}} 1: 1 \mathrm{v} / \mathrm{v}$ & 449 & 10 & 521 & 0.00983 \\
$5 \times 10^{-4} \mathrm{M} \mathrm{p} \mathrm{TSA}^{\mathrm{c}}$ in & 318 & 4 & & \\
ethanol & 332 & 17.0 & 528 & 0.00222 \\
$\mathrm{CH}_{3} \mathrm{COOH}: \mathrm{EtOH}^{\mathrm{b}}$ & 465 & 12.6 & & \\
$1: 1 \mathrm{v} / \mathrm{v}$ & 330 & 20.2 & 534 & 0.00116 \\
$5 \times 10^{-4}$ for N-Ph-Gly $^{\mathrm{d}}$ & 465 & 15 & & Very \\
in $\mathrm{EtOH}^{\mathrm{b}}$ & $393(\mathrm{sh})$ & 21.7 & 534 & low \\
\hline
\end{tabular}

${ }^{\mathrm{a}} \mathrm{TFA}=$ trifluoroacetic acid; ${ }^{\mathrm{b}} \mathrm{Absolute} \mathrm{EtOH} ;{ }^{\mathrm{c}}$ pTSA $=$ 4-toluenesulfonic acid, monohydrate; ${ }^{\mathrm{d}} \mathrm{N}-\mathrm{Ph}-\mathrm{Gly}=\mathrm{N}$-phenylglycine; ${ }^{\mathrm{e}}$ compared to quinine bisulfate (in $0.1 \mathrm{~N} \mathrm{H}_{2} \mathrm{SO}_{4}, \Phi=0.55$ ); ${ }^{\mathrm{f}} 6.51 \times 10^{-4} \mathrm{M}$.

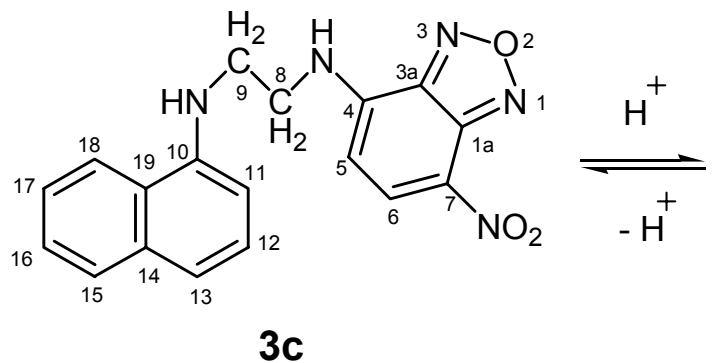

$3 c$

Scheme 3. The reversible protonation of 3c.

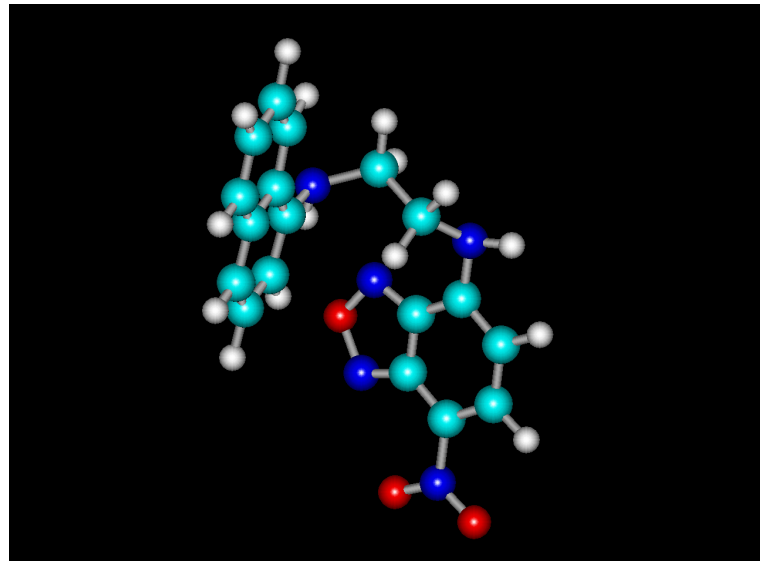

$3 c$

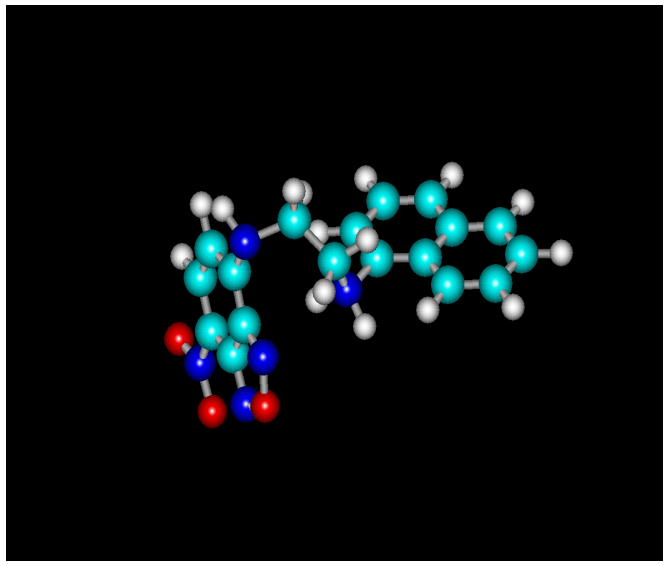

5

Figure 4. Optimized geometries (with the MM+ program from Hyperchem) for the nonfluorescent compound $\mathbf{3 c}$ and its conjugate acid $\mathbf{5}$ (Scheme 3 ). 
Qualitative experiments with compound 3c evidenced the fluorescence-enhancing effect of inorganic acids (e.g. $\mathrm{HCl}, \mathrm{H}_{2} \mathrm{SO}_{4}, \mathrm{H}_{3} \mathrm{PO}_{4}, \mathrm{HPO}_{3}, \mathrm{H}_{4}\left[\mathrm{Si}\left(\mathrm{W}_{3} \mathrm{O}_{10}\right)_{4}\right]$ ) or organic acids (e.g. bile acids, nicotinic acid, sulfanilic acid, salicylic acid, tannic acid). Compound $\mathbf{3 c}$ does not become fluorescent in the presence of benzoic, ascorbic, or caprilic acids, as well as $\alpha$-amino acids (i.e. leucine, alanine, phenylalanine, glycine, thyrosine, glutamic acid, arginine, ornitine).

\section{Fluorescence of compound $3 f$}

It was shown earlier that compounds $\mathbf{3 e}, \mathbf{3 f}$, and $\mathbf{3 g}$ have the highest fluorescence in the series examined in this report. The hydrophobicity of these compounds decreases in the order $\mathbf{3 e}>\mathbf{3 g}>$ 3f. The last compound is actually amphiphilic due to the presence of the hydrophobic NBD moiety, and the hydrophilic tris(hydroxymethyl) group. We examined the behavior of the fluorescence of $\mathbf{3 f}$ in aqueous ethanol as a function of the ethanol concentration. As shown in Fig. 5, the fluorescence intensity raises markedly with an increasingly higher ethanol content (about 20 times from $20 \%$ to $96 \%$ ethanol).

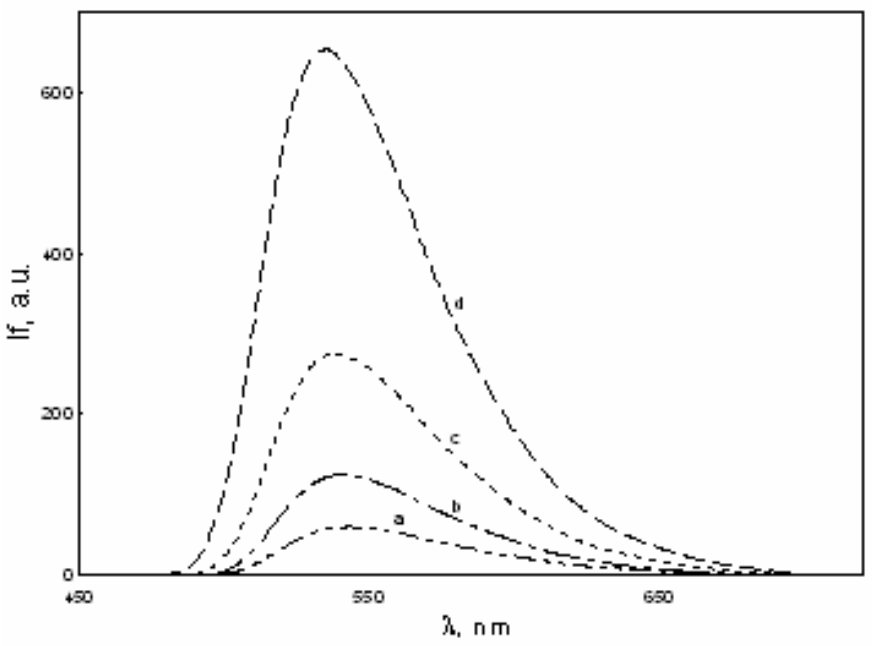

Figure 5. Change of the fluorescence intensity for compound $\mathbf{3 f}$ (conc. $=1.4 \times 10^{-3} \mathrm{M}, \lambda_{\mathrm{ex}}=450$ $\mathrm{nm}$ ) in aqueous ethanol: $\mathrm{a}=20 \%$ ethanol-water; $\mathrm{b}=40 \%$ ethanol-water; $\mathrm{c}=60 \%$ ethanolwater; $d=96 \%$ ethanol-water.

One can explain this behavior by the solvent polarity ${ }^{49-53}$ and/or by assuming that 3 f may form molecular aggregates like „multivalent molecules". ${ }^{54-58}$ Thus, compound 3f may be useful as a fluorescent probe for exploring how the stronger non-covalent interactions (hydrogen bonds, hydrophobic interactions, donor-acceptor or charge transfer interactions) behave for biomolecules such as glycoproteins, glycolipids, lectins. More generally, all strongly fluorescent compounds 3e, 3f, 3g may be useful as molecular fluorescent probes for antibody-antigen biochemical species that manifest affinity for 2,4-dinitrophenyl groups, which are similar to the NBD moiety. ${ }^{41,59}$ 


\section{Conclusions}

The present study was undertaken in order to obtain new 4-amino-7-nitro-NBD derivatives $\mathbf{3 b}$ $\mathbf{3 g}$ by reacting NBD-Cl with corresponding amines. The known 4-anilino derivative 3a, which is weakly fluorescent, was the reference compound. With a benzo-crown structure, $\mathbf{3 b}$ has ionophoric character. The weakly fluorescent $\mathrm{N}-\alpha$-naphthyl-N'-NBD-ethylenediamino derivative 3c becomes intensely fluorescent on treatment with strong acids, as the result of a change in geometry that cancels the intramolecular fluorescence quenching. The weakly fluorescent paramagnetic derivative 3d with an amino-TEMPO nitroxide group becomes intensely fluorescent on reduction with ascorbic acid yielding the corresponding hydroxylamine derivative. Compounds $\mathbf{3 e}$ with an $\alpha$-picolyl group and $\mathbf{3 g}$ with a hydroxylamino group are strongly fluorescent. Derivative 3f with a tris(hydroxymethyl) group has an amphiphilic character and may be useful as a molecular probe for studying emulsions and micelles. Other derivatives (3b-3d) may be useful as biochemical fluorescent probes.

\section{Experimental Section}

General Procedures. Chemicals (amines 2a-2g) and NBD-Cl (1) were Aldrich commercial products. The ${ }^{1} \mathrm{H}-\mathrm{NMR}$ and ${ }^{13} \mathrm{C}-\mathrm{NMR}$ spectra were recorded with a Varian Gemini 300BB spectrometer at $300 \mathrm{MHz}$ for protons and $75 \mathrm{MHz}$ for ${ }^{13} \mathrm{C}$. Electronic absorption spectra were recorded with a Perkin-Elmer Lambda UV-Vis spectrophotometer, and fluorescence with a Perkin-Elmer 204 spectrofluorimeter using an excitation lamp (Xe, $150 \mathrm{~W}$ ) interfaced with the computer, allowing a pre-established data reading time of $0.5 \mathrm{~s}$. EPR spectra were recorded using a Jeol JES FA100 spectrometer. IR spectra were recorded with a Bruker FTIR spectrophotometer Model Vertex 70, using ATR technique. Melting points have been recorded in open capillary with Electrothermal's IA 9000 Series of digital melting point instruments.

\section{Synthesis of compounds 3a-g. General procedure}

The 4-chloro-7-nitro-benzofurazan $\mathbf{1}$ was treated with amines $\mathbf{2 a - 2} \mathbf{g}$ in the following molar ratio: 1:1 for $\mathbf{3 b}, \mathbf{3 d}, \mathbf{3 e}$; $2: 1$ for $\mathbf{3 f}, \mathbf{3 g} ; 1: 2$ for $\mathbf{3} \mathbf{c}$ and a large excess (about 11:1) for 3a. The reaction medium (about $10 \mathrm{~mL} /$ gram of $\mathbf{1}$ ) was: acetonitrile for $\mathbf{3 a}$, methanol for $\mathbf{3 b}, \mathbf{3 c}, \mathbf{3 e}$, ethanol for 3d, 3f, and methanol:water 1:1,v/v for 3g. An excess (about $3 \mathrm{~mol} / 1 \mathrm{~mol}$ of 1) of sodium hydrogen carbonate was used for $\mathbf{3 b}-\mathbf{e}$ and $\mathbf{3 g}$. The mixture was stirred for one hour for $\mathbf{3 c}, \mathbf{3 g}$, two hours for $\mathbf{3 d}, \mathbf{3 f}$, and $24 \mathrm{hrs}$ for $\mathbf{3 a}, \mathbf{3 b}$, and $\mathbf{3 e}$ (at room temperature for $\mathbf{3 a}, \mathbf{3 b}, \mathbf{3 e}$, or at $50^{\circ} \mathrm{C}$ for $\mathbf{3 c}, \mathbf{3 d}, \mathbf{3 f}, \mathbf{3 g}$ ). The products $\mathbf{3 a - g}$ were isolated from the reaction mixture as follows:

(i) For 3a-3d and 3g after filtration through a G3 glass filter, the solution was shaken with a tenfold volume of $1 \mathrm{~N}$ hydrochloric acid and extracted with methylene chloride. The organic phase was dried over anhydrous sodium sulfate, and the solution was concentrated under reduced pressure. Compound 3a was obtained in pure state (confirmed by TLC, silica gel Merck $\mathrm{GF}_{254}$, 
$\mathrm{CH}_{2} \mathrm{Cl}_{2}$, once). Compounds $\mathbf{3 b}, \mathbf{3 c}, \mathbf{3 d}$, and $\mathbf{3 g}$ were isolated from the concentrated solution similarly by repeated preparative TLC, and was purified TLC using silica gel Merck $\mathrm{GF}_{254}$ and the following elution solvents: for $\mathbf{3 b}, \mathrm{CH}_{2} \mathrm{Cl}_{2}: \mathrm{MeOH}$ 9:1 (v/v), once; for $\mathbf{3 c}$ and $\mathbf{3 g}, \mathrm{CH}_{2} \mathrm{Cl}_{2}$ : twice; for 3d, $\mathrm{CH}_{2} \mathrm{Cl}_{2}: \mathrm{MeOH}$ 9.9:0.1 (v/v), once.

(ii) For 3e, the precipitate retained after filtration through a $\mathrm{G} 3$ glass filter was purified by preparative TLC using silica gel Merck $\mathrm{GF}_{254}$ with $\mathrm{CH}_{2} \mathrm{Cl}_{2}$ (three times).

(iii) For 3f, two consecutive extractions were performed: first with $\mathrm{CH}_{2} \mathrm{Cl}_{2}$ till the organic phase remained colorless, then with ethyl acetate till the organic phase was no longer fluorescent. The organic phase was dried over anhydrous sodium sulphate, the solution was concentrated under reduced pressure and the product was obtained in pure state by preparative TLC using silica gel Merck $\mathrm{GF}_{254}$ with $\mathrm{CH}_{2} \mathrm{Cl}_{2}: \mathrm{MeOH}$ 9:1 (v/v), three times.

4-Amino-7-nitro- $N$-phenyl-2,1,3-benzoxadiazole (3a). $95 \%$ yield, red solid, m.p. $151-152^{\circ} \mathrm{C}$ (lit. m.p. $150^{\circ} \mathrm{C}^{1}$ and $152-153^{\circ} \mathrm{C}^{12}$ ); Anal.: Calcd. for $\mathrm{C}_{12} \mathrm{H}_{8} \mathrm{~N}_{4} \mathrm{O}_{3}$ : C 56,26; H 3.15; N 21.87; found C 56.24; H 3.10; N 21.81; IR (ATR), $\mathrm{cm}^{-1}$ : $1554\left(\mathrm{NO}_{2}\right), 3289(\mathrm{NH})$.

4-(4'-Aminobenzo-18-crown-6)-7-nitro-2,1,3-benzoxadiazole (3b). 72\% yield, red solid, m.p. 147-148 ${ }^{\circ}$; Anal.: Calcd. for $\mathrm{C}_{22} \mathrm{H}_{26} \mathrm{~N}_{4} \mathrm{O}_{9}$ : C 53,88; $\mathrm{H}$ 5.34; $\mathrm{N} \mathrm{11.42;} \mathrm{found} \mathrm{C} 53.85 ; \mathrm{H} \mathrm{5.33;} \mathrm{N}$ 11.38; IR (ATR), $\mathrm{cm}^{-1}: 1566\left(\mathrm{NO}_{2}\right), 2912\left(\mathrm{CH}_{2}\right), 3520(\mathrm{NH})$.

$\boldsymbol{N}$-1-Naphthyl- $\boldsymbol{N}^{\prime}$-(7-nitro-2,1,3-benzoxadiazole-4-yl)ethane-1,2-diamine (3c). $68 \%$ yield, red-brown solid, m.p. 195-196 ${ }^{\circ}$; Anal.: Calcd. for $\mathrm{C}_{18} \mathrm{H}_{15} \mathrm{~N}_{5} \mathrm{O}_{3}$ : C 61,88; $\mathrm{H} 4.32$; N 20.04; found C 61.85; H 4.30; N 20.00; IR (ATR), $\mathrm{cm}^{-1}$ : $1574\left(\mathrm{NO}_{2}\right), 2924\left(\mathrm{CH}_{2}\right), 3327(\mathrm{NH})$. On treatment with the acids mentioned in the text and Table 2, a strong fluorescence due to the salt 5 is observed.

4-(Amino-2',2',6',6'-tetramethylpiperidinyloxy)-7-nitro-2,1,3-benzoxadiazole $\quad$ (3d). $\quad 16 \%$ yield, red-brown solid, m.p. 235-236 ${ }^{\circ} \mathrm{C}$; Anal.: Calcd. for $\mathrm{C}_{15} \mathrm{H}_{20} \mathrm{~N}_{5} \mathrm{O}_{4}$ : C 53,88; $\mathrm{H} \mathrm{6.02;} \mathrm{N}$ 20.94; found C 53.85; H 6.00; N 20.88; IR (ATR), $\mathrm{cm}^{-1}: 1313$ (N-O), $1577\left(\mathrm{NO}_{2}\right), 2932,2980$ $\left(\mathrm{CH}_{2}, \mathrm{CH}_{3}\right), 3215(\mathrm{NH})$.

7-Nitro- $N$-(pyridine-2-yl-methyl)-2,1,3-benzoxadiazole (3e). 52\% yield, yellow-reddish solid, m.p. 194-195 ${ }^{\circ} \mathrm{C}$; Anal.: Calcd. for $\mathrm{C}_{12} \mathrm{H}_{9} \mathrm{~N}_{5} \mathrm{O}_{3}$ : C 53,14; $\mathrm{H} 3.34 ; \mathrm{N} 25.82$; found $\mathrm{C} 53.11$; $\mathrm{H} 3.33$; N 25.77; IR (ATR), $\mathrm{cm}^{-1}: 1581\left(\mathrm{NO}_{2}\right), 2920\left(\mathrm{CH}_{2}\right), 3293(\mathrm{NH})$.

2-(Hydroxymethyl)-2-[(7-nitro-2,1,3-benzoxadiazole-4-yl)amino]propane-1,3-diol (3f). 22\% yield, dark brown solid, m.p. 216-217 ${ }^{\circ} \mathrm{C}$; Anal.: Calcd. for $\mathrm{C}_{10} \mathrm{H}_{12} \mathrm{~N}_{4} \mathrm{O}_{6}$ : C 42,26; $\mathrm{H} 4.25$; N 19.71; found C 42.23; H 4.21; N 19.67; IR (ATR), $\mathrm{cm}^{-1}: 1576\left(\mathrm{NO}_{2}\right), 2923\left(\mathrm{CH}_{2}\right), 3277,3354$ $(\mathrm{OH})$.

4-Amino- $N$-hydroxy- $N$-methyl-7-nitro-2,1,3-benzoxadiazole (3g). $17 \%$ yield, brown-reddish solid, m.p. $235-236^{\circ} \mathrm{C}$; Anal.: Calcd. for $\mathrm{C}_{7} \mathrm{H}_{6} \mathrm{~N}_{4} \mathrm{O}_{4}$ : C 40,00; $\mathrm{H} 2.87$; N 26.66; found C 39.96; $\mathrm{H}$ 2.84; N 26.60; IR (ATR), $\mathrm{cm}^{-1}: 1579\left(\mathrm{NO}_{2}\right), 2920\left(\mathrm{CH}_{3}\right), 3292(\mathrm{OH})$.

\section{Reduction of compound 3d to 4 (Scheme 2)}

A six-fold molar excess of ascorbic acid was added to the solution of $\mathbf{3 d}$ in absolute ethanol under stirring at room temperature till TLC shows the disappearance of $\mathbf{3 d}$ and the complete 
formation of $4\left(\mathrm{R}_{\mathrm{f}} \mathbf{3 d}=0.907, \mathrm{R}_{\mathrm{f}} \mathbf{4}=0.372\right.$, silica gel, $\mathrm{CH}_{2} \mathrm{Cl}_{2}: \mathrm{MeOH} 9.5: 0.5(\mathrm{v} / \mathrm{v})$, detection by $\mathrm{UV}$ at $254 \mathrm{~nm}$ and $360 \mathrm{~nm}$, Figure 3.

\section{References}

1. Ghosh, P. B.; Whitehouse; M. W. J. Med. Chem. 1968, 11,305.

2. Ghosh, P. B.; Whitehouse, M. W. Biochem. J. 1968, 108, 155.

3. Birkett, D. J.; Price, N. C.; Radda, G. K.; Salmon, A. G. FEBS Lett. 1970, 6, 346.

4. Kenner, R. A.; Aboderin, A. A. Biochemistry 1971, 10, 4433.

5. Lawrence, J. F.; Frei, R. W. Anal. Chem. 1972, 44, 2046.

6. Klimisch, H.-J.; Stadler, L. J. Chromatogr. 1974, 90, 141.

7. Hoff, F. V.; Heyndrickx, A. Anal. Chem. 1974, 46, 286.

8. Imai, K.; Toyo'oka, T.; Miyano, H. Analyst 1984, 109, 1365.

9. Matsumoto, K.; Ichitani, Y.; Ogasawara, N.; Yuki, H.; Imai, K. J. Chromatogr. A, 1994, $678,241$.

10. Halle, J.-C.; Mokhtari, M.; Soulie, P.; Pouet, M.-J. Can. J. Chem., 1997, 75, 1240.

11. Santa, T.; Takeda, A.; Uchiyama, S.; Fukushima, T.; Homma, H.; Suzuki, S.;Yokosu, H.; Lim, C.K.; Imai, K. J. Pharm. Biomed. Anal., 1998, 17, 1065.

12. Uchiyama, S.; Santa, T.; Fukushima, T.; Homma, H.; Imai, K. J. Chem. Soc., Perkin Trans. 2, 1998, 2165.

13. Al-Kindy, S.; Santa, T.; Fukushima, T.; Homma, H.; Imai, K. Biomed. Chromatogr., 1998, $12,276$.

14. Oe, T.; Morita, M.; Toyo’oka T. Anal. Sci., 1999, 15, 1021.

15. Uchiyama, S.; Santa, T.; Imai, K. J. Chem. Soc., Perkin Trans. 2, 1999, 569.

16. Uchiyama, S.; Santa, T.; Imai, K. J. Chem. Soc., Perkin Trans. 2, 1999, 2525.

17. Uchiyama, S.; Santa, T.; Imai, K. Analyst, 2000, 125, 1839.

18. Uchiyama, S.; Santa, T.; Okiyama, N.; Fukushima, T.; Imai, K. Biomed. Chromatogr., 2001, $15,295$.

19. Onoda, M.; Uchiyama, S.; Santa, T.; Imai, K. Luminiscence, 2002, 17, 11.

20. Onoda, M.; Uchiyama, S.; Endo, A.; Tokuyama, H.; Santa, T.; Imai K. Org. Lett., 2003, 5, 1459.

21. Bem, M.; Caproiu, M.T.; Vasilescu, M.; Tudose, M.; Socoteanu, R.; Nicolae, A.; Constantinescu, T.; Banciu, M.D. Rev. Roum. Chim., 2003,48, 709.

22. Lakshmi, C.; Hanshaw, R.G.; Smith, B.D. Tetrahedron, 2004, 60, 11307.

23. Toyo'oka, T. Curr. Pharm. Anal., 2005, 1, 57.

24. Crampton, M.R.; Delaney, J.; Rabbitt, L.C. J. Chem. Soc., Perkin Trans. 2, 1999, 2473.

25. Bem, M.; Caproiu, M.T.; Stoicescu, D.; Constantinescu, T.; Balaban, A.T. Central Eur. J. Chem., 2003, 3, 260. 
26. Bem, M.; Culita, D.C.; Caproiu, M.T; Constantinescu, T.; Banciu, M.D. Rev. Roum. Chim., 2003, 48, 387.

27. Bem, M.; Vasilescu, M.; Caproiu, M.T.; Draghici, C.; Beteringhe A.; Constantinescu, T.; Banciu, M.D.; Balaban, A.T. Central Eur. J. Chem. 2004, 2, 672.

28. Moutires, G.; Pinson, J.; Terrier, F.; Goumont, R. Chem. Eur. J., 2001, 7, 1712.

29. Makosza, M.; Winiarski, J. Acc. Chem. Res., 1987, 20, 282.

30. Hansch, C.; Leo, A. Substituent Constants for Correlation Analysis in Chemistry and Biology, Wiley, New York, 1979.

31. Cserhati, T. Anal. Chim. Acta, 1994, 292, 17.

32. Cserhati, T.; Forgacs, E. J. Chromatogr. A, 1994, 660, 313.

33. Kossoy, A.D.; Risley, D.S.; Kleyle, R.M.; Nurok, D. Anal. Chem., 1992, 64, 1345.

34. Soczewinski, E. Anal. Chem., 1969, 41, 179.

35. Calvino, R.; Gasco, A.; Leo, A. J. Chem. Soc., Perkin Trans. 2, 1992, 1643.

36. Terrier, F.; Chatrousse, A.-P.; Millot, F. J. Org. Chem., 1980, 45, 2666.

37. Mulliken R. S. J. Chem. Phys., 1955, 23, 1833.

38. Katritzky, A. R.; Lobanov V. S.; Karelson, A. CODESSA: A Reference Manual (Version 2.0), Gainesville, Florida, 1994.

39. Weber, E.; Toner, J.L.; Goldberg, I.; Vögtle, F.; Laidler, D.A.; Stoddart, J.F.; Bartsch, R.A.; Liotta, C.L. Crown Ethers and Analogs, Wiley, Chichester, 1989, p. 7.

40. Vögtle, F. Supramolecular Chemistry, Wiley, 1991, p.27.

41. Haugland, R.P. The Handbook. A Guide to Fluorescent Probes and Labeling Technologies, $10^{\text {th }}$ edition, Molecular Probes, 2005, pp. 87, 105, 127, 272, 591, 610, 618, 713, 794, 873.

42. Reichardt, C. Solvents and Solvent Effects in Organic Chemistry, $3^{\text {rd }}$ ed., Wiley-VCH, 2003 , p. 352.

43. Strickler, S.J.; Berg, R. J. Chem. Phys., 1962, 37, 814.

44. Suzuki, T.; Obi, K. Chem. Phys. Letters, 1995, 246, 130.

45. Szajdzinska-Pietek, E.; Wolszkzak, M. Chem. Phys. Letters, 1997, 270, 527.

46. Mischie, A.; Maior, O.; Badea, F.; Vasilescu, M.; Caragheorgheopol, A.; Caldararu, H.; Socoteanu, R.; Pencu, G.; Constantinescu, T. Rev. Roum. Chim., 2001, 46, 107.

47. Forrester, A.R.; Hay, J.M.; Thomson, R.H. Organic Chemistry of Stable Free Radicals, Academic Press, London, 1968, p. 180; Tudose, M.; Ionita, P.; Dumitrascu, F.; Draghici, C.; Caproiu, M. T.; Covaci, I. C.; Constantinescu, T.; Banciu, M. D.; Balaban, A. T., Arkivoc 2005 (iv), 225.

48. www.hyper.com/products/evaluation/hyper75/default.html.

49. Buncel, E.; McKerrow, A.J.; Kazmaier, P.M. J. Chem. Soc., Chem. Commun., 1992, 1242.

50. Das, S.; Thanulingam, T.L ; Thomas, K.A.; Kamat, P.V.; George, M.V. J. Phys. Chem., 1993, 97, 13620.

51. Das, S.; Thomas, K.G.; Ramanathan, R.; George, M.V.; Kamat, P.V. J. Phys. Chem., 1993, 97, 13625.

52. Song, Q.; Evans, C.E.; Bohn, P.W. J. Phys. Chem., 1993, 97, 13736. 
53. Das, S.; Thomas, K.G.; Thomas, K.J.; Kamat, P.V.; George, M.V. J. Phys. Chem., 1994, 98, 9291.

54. Baldini, L.; Casnati, A.; Sansone, F.; Ungaro, R. Chem. Soc. Rev., 2007, 36, 254.

55. Mammen, M.; Choi, S.-K.; Whitesides, G.M. Angew. Chem., Int. Ed., 1998, 37, 2755.

56. Varki, A. Glycobiology, 1993, 3, 97.

57. Ercolani, G. J. Am. Chem. Soc., 2003, 125, 16097.

58. Kitov, P.I.; Bundle D.R. J. Am. Chem. Soc., 2003, 125, 16271.

59. Lancet, D.; Pecht, I. Biochemistry, 1977, 16, 5150. 